\title{
Świat czy wydarzenie? W stronę ontologii wojny
}

\author{
Adam WOŹNIAK*
}

\begin{abstract}
The world or an event? Towards an ontology of war: This paper is an attempt to rethink the ontology of war. Its main object is to determine the ontological status of war and the connection between strategies of armed conflict prevention and the way this status is understood. If to overcome metaphysics we need to reconsider its basis then maybe a similar strategy should be applied in order to overcome war. The source of war is understood here not only in temporal terms, but also as its essence - the ontological basis. The first part of the article invokes several conceptions from the twentieth century (that, of course, refer to much older texts), according to which, war was to be overcome by variously understood progress. In those conceptions, as well as in the critical approaches from the beginning of the 21 st century, war is treated as an event, a state of affairs. In the next part of my paper, based on Margaret Mead's anthropological diagnosis, I propound a conception of war as an invention, and therefore - technology. The issue of war is further considered in the context of the twentieth century philosophy of technology. A thesis is put forward according to which understanding the influence of techne of war over episteme should be the essence of thinking of war prevention. In this study, war is treated as a technology that determines perception. For critical reflection upon war, I use twentieth century philosophical conceptions linking technology with cognitive processes, especially those formulated by Martin Heidegger and Marshall McLuhan.
\end{abstract}

\section{KEYWORDS}

war; Marshall McLuhan; Martin Heidegger; technology

* Doktorant w Instytucie Filozofii Uniwersytetu Jagiellońskiego. E-mail: aadam.wozniak@ gmail.com. 


\section{WPROWADZENIE}

O kresie wojen można myśleć przynajmniej na dwa sposoby. W obrębie pierwszego z nich mieści się przekonanie, że przestaną się one wydarzać wskutek, moralnie czy technologicznie pojętego, postępu (Freud, 2009: 29; Toffler \& Toffler, 2006: 22). Jeśli powyższe przekonanie jest słuszne, to krytyczne studia nad wojną nie muszą stanowić samodzielnego problemu filozoficznego. Wojny staną się reliktem przeszłości niejako przy okazji rozwoju innych dziedzin, niezależnie od tego, w jakim stanie znajdować się będą badania nad konfliktami zbrojnymi. Wiara w związek postępu ze światowym pokojem podzielana była (jak zostanie pokazane poniżej) przez myślicieli zarówno na początku, jak i pod koniec XX wieku. Niestety optymistycznym rokowaniom wtórował zwykle szczęk karabinów i huk bombardowań.

W obrębie drugiego sposobu myślenia zwalczanie wojen nie może dokonać się bez gruntownego przemyślenia filozoficznych korzeni problemu (Barkawi \& Brighton, 2011) - w tym przede wszystkim zrozumienia, czym jest wojna w najbardziej podstawowym, metafizycznym sensie. Temu właśnie zagadnieniu poświęcony jest niniejszy tekst. Celem artykułu nie jest oczywiście ujęcie całości zagadnień ontologicznych wiążących się z wojną - a zagadnienie jej związków z techniką.

Pytanie badawcze brzmi: czy wojna może być rozumiana jako technika? Technika w znaczeniu zarówno techne (Lidell \& Scott, 1940: 1548), czyli środka do osiągania celów politycznych (Clausewitz, 2010), jak i heideggerowskiego, „.sposobu odkrywania”, a więc czegoś, co wyznacza ramy myśleniu (Heidegger, 2007: 14). Wobec tej drugiej możliwości w rozważania włączone zostaną idee Marshalla McLuhana dotyczące związków techniki z interpretacją procesów percepcyjnych (McLuhan, 1975). Wskazane zostaną dwie perspektywy rozumienia wojny - jako wydarzenia i jako środka technicznego wpisanego w klasyczną relację episteme-techne. To drugie ujęcie ma, w obrębie przyjętej tu optyki, charakter nadrzędny i to jemu w głównej mierze poświęcone zostaną rozważania.

Prowadzone poniżej badania zasadzają się na dwu fundamentach. Pierwszym z nich jest rozpoznanie Margaret Mead, zgodnie z którym wojna jest wynalazkiem, a więc zjawiskiem akcydentalnym, a nie źródłowo związanym z ludzką kondycją (Mead, 1990). Drugą podstawę stanowi natomiast dzielone przez Marshalla McLuhana i Martina Heideggera przekonanie o wpływie techniki (a więc wynalazków) na percepcję i myślenie (McLuhan, 1975; Heidegger, 2007). Synteza tych dwu stanowisk pozwala zapytać, czy krytyczny namysł nad wojną nie powinien kierować się ku filozofii techniki — nie zaś etyce, która często organizuje filozoficzne rozważania nad tym problemem. 


\section{WIEK}

Przydatnym wprowadzeniem, stanowiącym jednocześnie swego rodzaju uzasadnienie zasadności pogłębionych studiów nad wojną, będzie rzut oka na pierwszą z wyżej wymienionych grupę poglądów. Można się tu ograniczyć do minionego wieku, gdyż stanowi on reprezentatywny przykład rozdźwięku między optymistycznymi rokowaniami teoretyków a rzeczywistymi wydarzeniami politycznymi. Historię tego, bodaj najkrwawszego w dziejach, stulecia znaczyły momenty, w których do głosu dochodziło przekonanie, że oto podróż ku światu bez wojen jest bliska końca. Niedługo po zakończeniu I wojny światowej Sigmund Freud mógł więc już pisać o rozczarowaniu, które niósł ze sobą jej wybuch. U progu XX wieku wydawało się, że konflikty zbrojne są czymś niemożliwym wśród „kulturalnych” przedstawicieli kosmopolitycznej wspólnoty. Jeśli już miałyby wystąpić, to - ironizuje psycholog — tylko ,jako sposobność do wykazania się postępami w procesie rozwoju poczucia wspólnoty ogólnoludzkiej” (Freud, 2009: 29). Kilka lat przed wybuchem II wojny światowej Henry Ford twierdzif natomiast, że „ludzie są już zbyt inteligentni, by prowadzić konflikty zbrojne” (Toffler \& Toffler, 2006: 22) Po Shoah, Hiroszimie i Dreźnie przyszły konflikty w Korei i Wietnamie, które pochłaniając miliony ofiar, po raz kolejny brutalnie zaprzeczyły optymistycznym rokowaniom. Już w okolicach lat 90. XX wieku pojawiła się nowa fala przekonania o bliskim kresie wojny. Richard Rosecrance twierdził wtedy, że w niedalekiej przyszłości zmagania zbrojne zostaną zastąpione przez rywalizację ekonomiczną (Rosecrance, 1986). Hezjod wyprze więc Homera, dbałość o oikos zastąpi „wojenną zabawę”", a miecze zostaną przekute w lemiesze - to stary pomyst. I tym razem się jednak nie udało — ekonomia stała się raczej częścią wojennej machiny, niż ją zastąpiła.

Kres wielkim konfliktom zbrojnym miał też przynieść wieszczony przez Francisa Fukuyamę koniec historii (Fukuyama, 1991). Trzy lata po głośnym tekście amerykańskiego badacza wybuchła wojna w Zatoce Perskiej. Paradoksalnie i ona stała się podstawą do ukucia tezy o zmierzchu tradycyjnej wojny. Jean Baudrillard nazwał ją „martwą” (Baudrillard, 2006: 5), symularkum — czystą promocją, za którą nie stoi żaden produkt (Baudrillard, 2006: 17). W 1992 roku nadszedł niebędący już z pewnością symulakrum konflikt w Jugosławii, który pochłonął najwięcej ofiar wśród wszystkich europejskich starć od 1945 roku.

Przywoływanych przez Freuda optymistów początku wieku, Forda, Roserance'a, Fukuyamę i Baudrillarda różni oczywiście bardzo wiele. Tym, co ich łączy, jest wektor myślenia skierowany do przodu. Nie zawsze rzecz jasna szczególnie w przypadku Baudrillarda - mowa tu o postępie przyjmowanym z oświeceniową aprobatą. Punktem wspólnym jest jednak przekonanie, że

\footnotetext{
${ }^{1}$ „Nauczył nas [...] ziemię uprawiać Hezjod. A boski Homer — skąd dostąpił sławy? / Czyż nie stąd, że wojennej uczył nas zabawy?” (Arystofanes, 1977: 505).
} 
wojna zostanie niejako wyprzedzona przez ludzkość, że będziemy ją już mieli „za sobą".

Czy jednak odyseja, o której tu mowa, nie powinna przyjąć kierunku odwrotnego do mitycznej? Być może zamiast zostawić wojnę za sobą, należy skierować się właśnie ku niej i gruntownie ją przemyśleć? Potwierdzenie tej intuicji przynosi jeden z tekstów Martina Heideggera:

Myślenie przejściowe - pisze filozof z Fryburga — nie może ulec tej oto pokusie by coś, co ono w końcu i jako koniec pojęło, teraz pozostawić po prostu za sobą, miast nieść to ze sobą, tzn. teraz dopiero ująć tego czegoś istotę (cyt. za: Mizera, 2006: 18).

„Przezwyciężanie metafizyki - dodaje Janusz Mizera - oznacza jej przewinięcie do samych źródeł" (Mizera, 2006: 18). Wszystko wskazuje na to, że podobnie jest z przezwyciężaniem wojny. By to zrobić, należy przewinąć ją do samych źródeł i raczej „nieść ze sobą”, próbując ująć jej istotę, niż udawać, że już niedługo nie będzie nas dotyczyć. Wspomniane źródła nie muszą być początkiem w znaczeniu temporalnym - to znaczy pierwszymi (na przykład greckimi) ujęciami wojny. Mowa przede wszystkim o przybliżeniu się zrozumienia istoty wojny, a więc także odpowiedzi na pytanie, czy koniecznie należy postrzegać ją jako wydarzenie. Zabieg ten, nawet jeśli nie pozwoli na skuteczniejsze zapobieganie wojnom, to przynajmniej zbliży do zrozumienia klęsk dotychczasowych prób.

\section{KU ONTOLOGII WOJNY}

Początek XXI wieku przynosi próby takiego „przewinięcia”. W roku 2003 ukazuje się dysertacja Williama S. Mandricka The ontology of war (Mandrick, 2003), której celem było uchwycenie niezmiennych cech wojny przy pomocy Husserlowskiej redukcji ejdetycznej. Autor analizuje poszczególne przypadki wojennych wydarzeń i wyciąga z nich ekstrakt, który stanowić ma istotę wojny. Badacz sięga do rzadko spotykanego w analizach fenomenu wojny słownika pojęć, stosując między innymi wypracowaną przez Romana Ingardena koncepcję warstw. Wojna ma być zdaniem filozofa fenomenem zarówno fizycznym, jak $\mathrm{i}$ intencjonalnym, a przy tym warstwowym. Niezależnie od niestandardowego aparatu badawczego, w koncepcji Mandricka wojna pozostaje jednak zasadniczo wydarzeniem - „zawiera w sobie [...] procesy fizyczne takie jak manewry taktyczne, bitwy, kampanie" (Mandrick, 2003: 1; tłum. A.W.).

$\mathrm{Za}$ istotny $\mathrm{i}$ - przynajmniej w założeniu - programowy można uznać też tekst Taraka Barkawiego i Shane'a Brightona pt. Powers of war: Fighting, knowledge and critique (Barkawi \& Brighton, 2011). Autorzy wskazują w nim przede wszystkim na brak dyscypliny, dla której wojna stanowiłaby centralny punkt 
rozważań. Namysł nad nią obecny jest wprawdzie w obrębie historii, etnologii, etyki, archeologii i wielu innych dziedzin. Wszystkie one przyjmują już pewne rozumienie wojny, nie pytając, czym ona jest. Barkawi i Brighton postulują więc stworzenie gruntu pod war studies w postaci „zaniedbanej od czasów Heraklita” (Barkawi \& Brighton, 2011: 27) ontologii wojny. Ich własne rozważania podążają w dużym stopniu za Carlem von Clausewitzem i rozumieniem wojny jako walki (war as fighting). Według niemieckiego generała walka jest dla wojny tym, czym transakcje handlowe dla ekonomii - momentem ustalania wartości, wymiany słów na czyny i sprawdzania ich siły nabywczej (Clausewitz, 2010: 37). Choć koncepcja ta wydaje się na pierwszy rzut oka trafna, to jej zastosowanie do nowoczesnych konfliktów bywa krytykowane między innymi z perspektywy myśli Baudrillarda (war as processing) (Nordin \& Öberg, 2014). Zdaniem francuskiego socjologa w przypadku współczesnej wojny przygotowania do transakcji nie zostają nigdy zakończone wymianą. Wojna w Zatoce powiada Baudrillard - była ciągła promocją, której głównym celem miało być ukrycie faktu, że promowany produkt nie istnieje (Baudrillard, 2006: 17). Jak łatwo zauważyć, opis autora Symulakrów i symulacji stanowi negację ujęcia Clausewitza, a więc pozostaje w obrębie zarysowanych przez niego pól. Obaj badacze posługują się zresztą podobną, quasi-ekonomiczną terminologią. Wojna powinna być wydarzeniem — walką, a konflikt w Zatoce Perskiej nie obfitował w takie momenty, więc w istocie „wojny w zatoce nie było”.

Truizmem jest stwierdzenie, że wojenne wydarzenia wiążą się z walką, przygotowaniem do niej lub - w wersji Baudrillarda - pozorowaniem przygotowań. Czy jednak, myśląc o istocie wojny, musimy mieć na myśli wydarzenia? W Cynkowych chłopcach Swietłana Aleksijewicz stwierdza coś przeciwnego „wojna to świat, a nie wydarzenie” (Aleksiejewicz, 2015: 23). Co może to znaczyć? Ważną wskazówkę interpretacyjną przynosi wspomniany już tekst brytyjskich badaczy, którzy zwracają uwagę na związek wojny z poznaniem, wyrażany przez pojęcie war-truth. Wojna jest dla nich nie tylko wydarzeniem, ale także narzędziem konstruowania prawdy, organizatorem dyskursu i percepcji (Barkawi \& Brighton, 2011). Może być wprawdzie rozumiana jako sytuacja, lecz także jako coś, co buduje dyskursywny grunt pod ową sytuację. Za źródłowe, jak zamierzam pokazać, należy uznać to drugie znaczenie. Wojna byłaby więc systemem organizacji świata - być może na tyle skutecznym, by zostać wreszcie uznana za tożsamą z owym światem („wojna to świat”).

Czy więc, aby zrozumieć istotę wojny, wystarczy poddać analizie kilka jej „egzemplarzy” (to znaczy zespołów wydarzeń wojennych), wskazać cechy konieczne dla uznania ich za wojnę i zakończyć badania? Z pewnością jest to przydatne dla celów wojskowych, strategicznych, pozwala lepiej zrozumieć niezmienne prawa wojny czy — jak wolał kardynał John Henry Newman — „gramatykę prochu” (McLuhan, 1975: 51), ale nie oddaje jeszcze istoty tego, czym jest wojna na głębszym, fundującym wydarzenia poziomie. 


\section{CO TO ZNACZY, ŻE WOJNY NIE MA?}

Do uzasadnienia tego przekonania przybliży ujęcie go w nieco bardziej konkretnej formie. Jeśli więc wojna miałaby być stanem rzeczy — czymś, co z braku lepszego terminu nazwać można „treścią świata”, to miałaby swój początek i koniec. Tak też rzeczywiście używa się tego słowa na co dzień - słyszymy się więc, że gdzieś wojna się kończy, a gdzie indziej zaczyna. W tym sensie możliwy — choć trudny do osiągnięcia — jest stan rzeczy, w którym „nie ma wojny”, to znaczy akurat nie przydarza się ona w żadnym miejscu na świecie. Od 1945 do 1990 roku zdarzyły się trzy tygodnie, w których nie toczyła się żadna wojna (Toffler \& Toffler, 2006: 21). Był to czas pokoju. Tym, czego w nim „brakowało”, była wojna jako część opozycji wojna-pokój. Istniało jednak coś, co pozwalało rozumieć wojnę i pokój jako potencjalny zestaw wydarzeń.

W głębszym sensie stan zarówno wojny, jak i pokoju, jest fundowany przez Wojnę pojmowaną szerzej. By dana społeczność rozumiała, że żyje w pokoju, musi znać ideę wojny, czyli — jakkolwiek by to nie brzmiało — wynaleźć wojnę. W opublikowanym po raz pierwszy w roku 1940 artykule Mead stawia pytanie: czy wojna jest biologiczną koniecznością, nieuniknioną konsekwencją rozwoju społeczeństw, czy też „złym wynalazkiem” (Mead, 1990: 1). Termin „wynalazek” rozumiany jest przez autorkę szeroko i obejmuje tyleż pismo, co instytucję małżeństwa czy procesu sądowego. Pewne wynalazki - jak umiejętność krzesania ognia - pojawiają się w każdej społeczności. Zdaniem badaczki są one mylnie traktowane jako nieodłączny, wynikający z ludzkiej natury, atrybut człowieczeństwa (Mead, 1990: 1). Tak też bywa z wojną — choć zdaniem antropolożki nie jest ona wynalazkiem obecnym w każdej społeczności. Jako uzasadnienie tego przekonania autorka podaje przykład Eskimosów, którzy pomimo sprzyjających warunków (wysokiego poziomu osobniczej agresji, indywidualnych walk o przywództwo w grupie etc.) nie mają w swoim słowniku odpowiednika choćby wojny defensywnej. Eskimosi są więc agresywni, ale ich agresja nie prowadzi do grupowych, zorganizowanych starć militarnych (Mead, 1990: 2).

Jeśli przyjmiemy, że wynalazek warunkuje myślenie o jego aktualnym braku (McLuhan, 1975: 79), to ontyczną opozycję wojna-pokój można uznać za konsekwencję wynalezienia Wojny, która jest czymś innym niż ontyczne wydarzenie. Odpowiedź na pytanie: czy w trakcie tygodniowej przerwy między wojnami Wojna istnieje?, brzmi więc: tak — jeśli mamy na myśli sens ontologiczny. Wojna nie jest bowiem wydarzeniem, lecz wynalazkiem. Gdyby nagle, w wyniku nieprawdopodobnego zbiegu okoliczności, ze świata zniknęły wszystkie egzemplarze samochodów, to w kwestii istnienia samochodu jako wynalazku niewiele by się zmieniło. Pozostałyby jeszcze plany i linie produkcyjne, które pozwoliłyby na łatwą rekonstrukcję. Możliwość powołania do istnienia zupełnie wystarcza. Samochód nie jest tu in potentia (Arystoteles, 1996: 34-78) i nie domaga się aktualizacji. Jest — by tak rzec — pełnią bycia właściwego 
wynalazkom. Podobnie jest z wojną. W trakcie pokoju istnieje ona jako możliwość, która wyznacza ramy działaniom. Już jako taka odciska ogromne piętno na życiu społeczno-politycznym. Wpływa na organizację architektoniczną miast (Virillo, 2008: 22), wydatki rządów, rozumienie cnoty (Jaeger, 1962: 38) i postrzeganie relacji z sąsiednimi państwami. Wracając do koncepcji Mandricka, stwierdzić można, że wojna rzeczywiście przypomina swym sposobem istnienia dzieło sztuki, ale jest to dzieło konceptualne, które nie musi zostać „zmaterializowane", by wywrzeć wpływ.

\section{MEDIUM CZY MESSAGE}

Uznanie wojny za wynalazek rodzi jednak wiele pytań. W kontekście prowadzonych tu rozważań najistotniejsze brzmi: w jaki sposób wytłumaczyć wskazaną przez Barkawiego i Brightona relację między nim a wiedzą? Wiedząc, czym jest wojna, trzeba też zapytać, „jak” ona jest. By wejść głębiej w interesujące nas zagadnienia, należy zadać pytanie ontologiczne ${ }^{2} \mathrm{w}$ znaczeniu zbliżonym do Heideggerowskiego. Pytanie o byt - czym jest wojna? - powinno zostać zastąpione rozważaniem nad tym, co znaczy „jest” w zdaniu „wojna jest”. Może dopiero wtedy okaże się, dlaczego przywoływane wcześniej XX-wieczne próby sprowadzenia wojny do nie-bytu musiały skończyć się niepowodzeniem.

Odwołanie do myśli wczesnego Heideggera ma charakter czysto narzędziowy - porządkuje myślenie, umieszczając je w ramach intuicyjnie zrozumiałej różnicy ontologicznej. Kwestię tę — przynajmniej na etapie wstępnego rozpoznania - da się równie dobrze przedstawić na inne sposoby. Można więc pomyśleć wojnę jako część ukutej przez McLuhana opozycji medium-message, to znaczy umieścić ją $\mathrm{w}$ relacji między treścią świata a tym, co ów świat organizuje i stwarza ramy dla przekazu. Ujęcie takie zwraca uwagę na fakt, że wojna jest nie tylko wydarzeniem, ale też medium, soczewką, która strukturyzuje rozumienie polityki międzynarodowej. Owo medium może być sposobem przetwarzania społecznych emocji — narzędziem służącym do zarządzania ludźmi, które jest znane jednym społecznościom, a zupełnie obce innym. Odwołując się do Ludwiga Wittgensteina, można wreszcie powiedzieć, że nie jest ona faktem czy przedmiotem, lecz formą, czyli sposobem, w jaki przedmioty wiążą się w stanie rzeczy” [2.0.3.2] $]^{3}$, „możliwością struktury” [2.033]. W rzeczy samej

${ }^{2}$ Do opozycji ontyczny-ontologiczny odwoływali się też Astrid H.M. Nordin i Dan Öberg we wspominanym już tekście. W sensie ontycznym badacze mówią o warfare jako praktyce, w znaczeniu ontologicznym o war jako naturze (istocie) tego, co ontyczne (Nordin \& Öberg, 2014: 393).

${ }^{3}$ Odniesienia do Traktatu logiczno-filozoficznego podaję, zgodnie z przyjętą konwencją, lokalizując je bezpośrednio w tekście głównym — poprzez podanie numeru tezy w nawiasie kwadratowym. Cytaty pochodzą z: Wittgenstein, 1997. 
wojna jako wynalazek jest właśnie strukturalną możliwością zaistnienia wojny. Jak powiada Arystoteles:

Badając przyczyny różnych rzeczy należy zawsze wykrywać przyczynę najwyższą [...] oto człowiek buduje, ponieważ jest budowniczym, a jest budowniczym dzięki znajomości sztuki budowania (Arystoteles, 2010: 96).

Najwyższą przyczyną wojny jest jej przyczyna formalna, a więc — parafrazując Stagirytę — znajomość sztuki wojowania, jej „formy i modelu” (Arystoteles, 2010: 94), czyli istnienie wojny jako wynalazku. Ku eksploracji jej formalnych umocowań kieruje się też niekiedy intuicja tych, których doświadczyła ona najboleśniej. W przemówieniu z 27 stycznia 2020 roku były więzień Auschwitz Marian Turski mówi:

obiecuję wam młodzi, że nie będę wam opowiadał o moich cierpieniach, nie będę wam opowiadał o moich przeżyciach, o moich dwóch marszach śmierci, o tym jak kończyłem wojnę, ważąc 32 kilo, zupełnie już na skraju życia, wyczerpania [...] Chciałbym mojej córce, moim wnukom, ich pokoleniom powiedzieć o was samych. Widzę, że jest między nami pan prezydent Austrii pan Alexander van der Bellen. Pamięta pan panie prezydencie, kiedy gościł pan mnie i kierownictwo międzynarodowego komitetu oświęcimskiego, kiedy mówiliśmy o tamtych czasach. W pewnym momencie pan użył takiego sformułowania „Auschwitz nie spadło z nieba”. [...] jest w tym niesłychanie głęboki, bardzo ważny do zrozumienia skrót myślowy (Turski, 2020).

Turski postanawia, że nie będzie opowiadał historii swojego życia. Nie zdaje sprawy z relacji między bytami, lecz stawia kwestię ontologiczną. „Auschwitz nie spadło z nieba" to znaczy, że przyszło wolniej niż grom i skądinąd niż z przestworzy. Były więzień pyta o umocowanie formalne, ontologiczne, ideologiczne - może zresztą w tym przypadku jest to jedno i to samo. W każdym razie Turski zadaje pytanie o bycie i po części, per negationem, na nie odpowiada. Zadaniem, które podjęte zostanie w dalszej części tekstu, jest sformułowanie odpowiedzi pozytywnej. Jak istniało Auschwitz przed 1942 rokiem? Jak istniała możliwość II wojny światowej i każdej innej wojny? Wreszcie — jak istnieje wojna dziś i jakie ma to konsekwencje dla naszej percepcji?

\section{WOJNA A TECHNIKA}

Odpowiedź na zadane powyżej pytania może być prosta: wszystkie te wydarzenia istniały i dalej istnieją jako formalna możliwość wynikająca z wynalezienia wojny jako narzędzia politycznego. Narzędzie to stanowi technikę w szerokim, Jüngerowskim sensie, obejmującym ogół środków usprawniających realizację celu. Co istotne, technika w tym znaczeniu nie tylko pozwala realizować 
potrzeby, lecz także je organizuje. „Czyniąc to - pisze Jünger — zmusza człowieka, by jej stużył" (Jünger, 2016: 101).

Cóż jednak odkrywczego oferuje zwrócenie uwagi na techniczny charakter wojny? Myślenie o jej związku z wynalazkami, a więc techniką, ma przecież długą tradycję. W obrębie tej tradycji znajdują się jednak dwa główne nurty, których zadaniem nie jest bynajmniej eksploracja „techniczności” wojny dla niej samej. Zadaniem pierwszego z nich jest przede wszystkim rozważanie wpływu postępu technologicznego na prowadzenie wojen. Najlepszym przykładem jest szeroko dyskutowana rewolucja militarna XVII wieku i jej związek z rozpowszechnieniem prochu. Badania takie dotyczyć mogą też między innymi wpływu wynalezienia taśmy produkcyjnej, czołgów, samolotów czy dronów na sposób, w jaki ludzie walczą. W obrębie drugiego nurtu wojna jest wprawdzie nazywana narzędziem, a nawet wynalazkiem, ale konstatacja ta stanowi raczej finał rozważań teoretycznych i nie znajduje rozwinięcia. Ze względu na cele badań postąpili tak Mead czy Clausewitz - który natychmiast po uznaniu, że wojna jest „narzędziem polityki” (Clausewitz, 2010: 468), przystępuje do tworzenia instrukcji obsługi tego narzędzia. Nic w tym jednak zaskakującego. Clausewitz był teoretykiem wojny w sensie ontycznego wydarzenia, a nie Wojny pojmowanej ontologicznie. Podobnie ma się sprawa z rozważaniami na temat tak zwanej wojny sprawiedliwej. Ich zadanie polega na ograniczaniu strat wywołanych użyciem techniki, a nie namysłem nad nią samą. Michael Walzer ma rację, gdy pisze, że filozofowie prowadzący głębsze badania nad wojną „są mało pomocni ludziom, którzy stają przed trudnym wyborem” (Walzer, 2010: 31). Rzeczywiście, ontologia wojny nie ograniczy konsekwencji konfliktów zbrojnych, podobnie jak namysł nad wpływem wynalezienia koła na organizację przestrzeni nie przyczyni się raczej do zmniejszenia liczby wypadków samochodowych. Wszystko to jednak być może pozwoli zrozumieć, że wojna jako narzędzie kreuje pola wyboru, a nie tylko pomaga je wypełniać — jest raczej szachownicą regulującą zakres możliwych ruchów niż tylko pionkiem.

\section{EPISTEME-TECHNE}

Jeśli więc chce się pomyśleć wojnę jako technikę i wyciągnąć z tego faktu możliwie najdalej posunięte wnioski, to należy zrozumieć jej relację z poznaniem. Wymaga to zwrotu ku relacji episteme-techne, której korzenie tkwią oczywiście w starożytnej Grecji. W klasycznym słowniku Henry'ego G. Liddella i Roberta Scotta znaleźć można cztery podstawowe znaczenia tecbne (Lidell \& Scott, 1940: 1548). Po pierwsze jest ono sztuką rękodzielniczą; po drugie „sztuczką" - w znaczeniu pejoratywnym; po trzecie oznacza sposób czy środki, dzięki którym można coś uzyskać (nie zawsze w kontekście rzemiosła) oraz zestaw reguł, system lub określoną metodę wykonywania czegoś; i wreszcie 
po czwarte - dzieło sztuki. Najbardziej przydatne w kontekście wojny jest oczywiście znaczenie trzecie, które jest też blisko definicji techniki ukutej przez Ernsta Jüngera.

Jeśli zaś mowa o relacji techne $i$ episteme, to warto wspomnieć, że jeszcze Ksenofont używał tych dwu terminów zamiennie (Parry, 2020). „Powiedz mi Kritobulu - pyta Sokrates w Ekonomiku - czy sztuka zarządzania domem

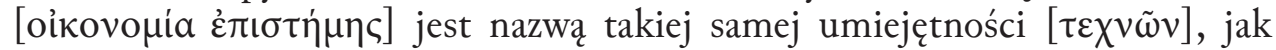
sztuka lekarska, kowalstwo, ciesielstwo?” (Ksenofont, 1857: 1). Pada odpowiedź twierdząca - zarządzanie domem jest więc techne i episteme, podobnie jak na przykład kowalstwo. Zdecydowanie jednak nie należy rozumieć tej relacji w kontekście częstego dziś przekładu techne jako rzemiosła (craft), episteme zaś jako wiedzy teoretycznej (knowledge), a tym bardziej jako części opozycji pomiędzy nauką „czystą” i stosowaną (Angier, 2010: 27). Jeśli różnica znaczeniowa pomiędzy tymi dwoma wyrazami istniała, to musiała być - szczególnie w kontekście filozoficznym - niewiele znacząca. Już w przypadku Platona najczęściej mówi się nie tyle o jedności, co o związku techne z poznaniem (Mizera, 2006: 100), choć i u niego (między innymi w Charmidesie) pojawiają się użycia synonimiczne (Parry, 2020). Co jednak o wiele istotniejsze, Platon używał techne (w znaczeniu craft) jako modelu ustanawiającego ramy epistemiczne, na których zbudowana została jego filozofia (Reeve, 2003: 39). Autor Państwa - pisze C.D.C. Reeve - „odkrył epistemologiczne niedostatki w rzemiosłach i opisał - przynajmniej w zarysie - podobną rzemiosłu naukę, która ich unika. Ta nauka, której pierwszą [...] zasadą jest Dobro samo w sobie, jest nadrzędnym rzemiosłem" (Reeve, 2003: 4). Obowiązująca w czasach klasycznych techne wyznaczyła więc Platonowi ramy myślenia. Mowa tu nie tylko o zakresie metafor i analogii, ale przede wszystkim o stworzeniu soczewki, przez którą oglądał on byty. Soczewka ta pozwoliła mu widzieć świat jako produkt rzemiosła, a stwórcę jako najdoskonalszego rzemieślnika. Techne jest więc nie tylko środkiem, ale także swego rodzaju formą w znaczeniu nadanym temu pojęciu przez Wittgensteina, czyli czymś, co wyznacza zakres możliwych stanów rzeczy.

Techne reguluje obszar tego, co jest „do pomyślenia”. Rzemiosło nie było oczywiście jedyną, a nawet nie pierwszą techne, która współkształtowała rozumienie bytów w obrębie europejskiej filozofii. Emmanuel Levinas twierdzi, że źródłowym paradygmatem postrzegania rzeczywistości była dla naszej kultury wojna. W Całości i nieskończoności czytamy:

Nie trzeba powoływać się na niejasne fragmenty Heraklita, by dowieść, że byt objawia się myśleniu filozoficznemu pod postacią wojny; że wojna ukazuje mu się nie tylko jako oczywisty fakt, ale także jako oczywistość sama - sama prawda rzeczywistości. W stanie wojny rzeczywistość zrzuca z siebie skrywające ją słowa i obrazy, by wyłonić się w swojej nagości i twardości (Levinas, 2002: 3). 
Nieco dalej francuski filozof dodaje, że wojna „posługuje się bronią, która obraca się przeciwko niej” oraz „ustanawia porządek, wobec którego nikt nie jest w stanie się zdystansować" (Levinas, 2002: 4-5). Wojna jest więc nakładanym na zmysły medium, które organizuje postrzeganie bytów. Jest nie tylko faktem, ale także światłem, które sprawia, że fakty jawią się tak, a nie inaczej. Levinas wpisuje ją w opozycję episteme-doxa, stwierdzając, że w czasie wojny opadają pozory i byt jawi się w swej nagości. O pewnej pierwotnej prostocie doświadczenia wojennego wspominają z kolei niekiedy żołnierze. Jeden z weteranów wojny w Afganistanie na zadane przez Aleksijewicz pytanie, czy mimo straconej w trakcie walk nogi wróciłby na pole bitwy, odpowiada twierdząco i uzasadnia: „tam przyjaciel to przyjaciel, a wróg to wróg. A tutaj stale to samo pytanie: za co zginęli moi koledzy? Za tych nażartych spekulantów? Urzędasów?” (Aleksijewicz, 2015: 80).

Wojna-pokój nie jest więc jedyną binarną ramą nakładaną przez wojnę na percepcję. Kolejną z nich jest opozycja swój-wróg. Pozostając w obrębie języka Levinasa, powiedzieć można, że zawiera ona w sobie obietnice zrównania In nego do tego samego, a więc oferuje swego rodzaju bezpieczeństwo poznawcze. Z drugiej jednak strony wiąże się nieodwołanie z możliwością destrukcji — utratą życia, zdrowia, relacji z bliskimi. W tym sensie Wojna nie tyle „posługuje się bronią, która obraca się przeciwko niej”, jak chciał francuski filozof, co sama jest bronią o strukturze farmakonu (Derrida, 1993) - lekarstwa i trucizny. Myślenie o wojnie jako farmakonie jest jednak myśleniem z głębi Wojny jako technicznego organizatora dyskursu. Lek i trucizna wzajemnie się potrzebują, a jednocześnie pragną ukryć fakt, że możliwe jest myślenie poza nimi.

\section{AUTONOMICZNY CHARAKTER WOJNY}

Opozycja swój-wróg ma oczywiście kluczowe znaczenie polityczne. Opisując jej znaczenie, Carl Schmitt powiada:

Nie sposób [...] zaprzeczać, że narody jednoczą się wokół przeciwstawnych pojęć wroga i przyjaciela, ani że również dzisiaj to przeciwieństwo faktycznie zachowuje znaczenie dla każdego narodu jako bytu politycznego (Schmitt, 2012: 256-257).

Autor Pojęcia polityczności podkreśla przy tym, że pojęcia wróg i przyjaciel mają charakter publiczny i nie wiążą się z osobistą animozją. Podobnie jest zwykle w przypadku żołnierzy walczących po przeciwnych stronach — ich wrogość jest sprawą publiczną, państwową — rzadko, a i wtedy najczęściej wtórnie wobec powodów politycznych, osobistą. Niemiecki filozof dodaje, że „wojna pozostaje realną możliwością, dopóki pojęcie wroga zachowuje sens” (Schmitt, 2012: 261). Pojęcie to ma zaś sens, gdy wiąże się z możliwością 
fizycznego unicestwienia, której najradykalniejszym wcieleniem jest wojna (Schmitt, 2012: 261). Roboczo uznać można, że „wróg” w rozumieniu polityki międzynarodowej oznacza „państwo, które przy nadarzającej się okazji jest skłonne zaatakować zbrojnie”. Pojęcie wojny ma więc sens, dopóki istnieje zagrażające danemu krajowi państwo (wróg), a pojęcie wroga, dopóki wojna jako groźba ostatecznego unicestwienia pozostaje realna. Owa kolistość jest kompatybilna z tezą Schmitta, zgodnie z którą pojęcia polityczne cechuje autonomia, to znaczy nie wykraczają one poza sferę polityczności (Schmitt, 2012: 254). Pozostają więc niezależne od etyki czy ekonomii.

Podobnie wsobna jest relacja wojna-pokój. Wojna oferuje pokój jako możliwość myślenia, a jednocześnie chce go osiągnąć tylko wojennymi metodami. „Chcesz pokoju szykuj się na wojnę” — brzmi główny imperatyw tego sposobu myślenia. Zdaniem McLuhana technika tworzy zapotrzebowanie na nią samą (McLuhan, 1975: 79). Wojna tworzy więc zapotrzebowanie zarówno na wojnę, jak i na pokój, który w tych ramach jest tylko antywojną wiążącą się ,ze strategicznym wykorzystaniem sily militarnej i ekonomicznej” (Toffler \& Toffler, 2006: 11). Dobrym przykładem tego, jak Wojna organizuje wydarzenia w obrębie osi wojna-pokój, są świadectwa dotyczące przyczyn wybuchu wojny peloponeskiej. Tukidydes powiada, że Lacedemończycy:

podjęli uchwałę o zerwaniu układu i konieczności wojny nie tyle z namowy sprzymierzeńców, ile ze strachu przed Ateńczykami. Widząc bowiem, że wielka część Hellady jest już opanowana przez Ateńczyków, bali się, żeby ich potęga jeszcze bardziej nie wzrosła (Tukidydes, 1988: 52).

Pokój był więc czasem przewidywania i przygotowań do wojny, a gdy możliwość konfliktu w późniejszym czasie zaczęła jawić się jako mniej korzystna, Spartanie zdecydowali się przystąpić do niego natychmiast (Lazenby, 2018: 40). U Tukidydesa czytamy też, że zgromadzenie Spartan zadecydowało, iż Ateńczycy złamali pokój i należy wypowiedzieć im wojnę (Tukidydes, 1988: 51). Koryntyjczycy z kolei przystąpili do wojny z Ateńczykami, gdyż ci wspierali w walce Korkyrejczyków. Wśród przyczyn wojny na próżno szukać takich, które wykraczałyby poza te wytwarzane przez Wojnę jako technikę. Powodem jest sojusz z wrogiem lub zerwanie pokoju, a więc nic, co sytuowałoby się poza wytyczanymi przez wojnę koleinami myślowymi. Podobne spostrzeżenia znaleźć można u Johana Huizingi, który o średniowiecznych sporach pisze tak: „ktokolwiek bada historię tych czasów, musi stwierdzić, że sprowadzenie tych konfliktów do przyczyn gospodarczo-politycznych jest niewystarczające" (Huizinga, 2018: 24).

Za jedną z głównych motywacji wojennych uważa badacz ochronę hono$\mathrm{ru}$ - rozumianego oczywiście przez pryzmat wytworzonej przez wojnę sieci odniesień. 
Wojna jako technika nie jest zatem wydarzeniem, lecz formą organizacji świata, czymś sytuującym się pod strukturą wydarzeń. Świat rozumiany jest tu po Heideggerowsku jako system sensownych odniesień (Heidegger, 1994: 91). Relacje w nim zorganizowane są przez binarne opozycje tak, że wojenne wydarzenia jawią się często jako nieuniknione. John F. Lazenby słusznie zauważa, że z naszej perspektywy wojna peloponeska nie była konieczna i równie słusznie dodaje „że współczesnym perspektywa ta nie była dana” (Lazenby, 2018: 53). Wydaje się, że jest tak z każdą wojną, a zadaniem krytycznych studiów nad nią musi być pytanie o to, dlaczego tak często wojna pozbawia nas jako „współczesnych" tej perspektywy. Krytyczne studia nad wojną powinny więc skupić się raczej na eksplorowaniu technicznych uwikłań ludzkiego myślenia niż na znajdującej się wewnątrz wojennego dyskursu problematyki etycznej. Zapobieganie wojnom metodami wojennymi i praca nad dekonstrukcją Wojny jako wynalazku to bowiem dwie różne rzeczy. To drugie ma w sobie więcej z namysłu nad techniką niż z moralności.

Levinas ma więc rację, gdy pisze, że prawdziwy pokój transcenduje świat (Kozak, 2014). Francuski filozof kieruje jednak swoje kroki ku moralności i eschatologii. Można jednak pójść w drugą stronę i stwierdzić, że pokój taki powinien przekraczać świat rozumiany jako zestaw binarnych opozycji fundowanych przez wojnę jako technikę. W którym jednak miejscu rozpocząć namysł nad relacją techniki wojennej i percepcji oraz nad wpływem wynalezienia wojny na ludzkie myślenie? Wydaje się, że XX wiek położył solidne podwaliny pod podobne rozważania w postaci myśli Heideggera i McLuhana. Ten pierwszy pisze:

Technika nie jest tylko środkiem. Technika jest sposobem odkrywania. Jeśli zwrócimy na to uwagę otworzy się przed nami zupełnie inny obszar dla istoty techniki. Jest to obszar odkrycia, tzn. prawdy (Heidegger, 2007: 14).

Istnienie wojny jako technicznego narzędzia prowadzenia polityki wpływa na horyzont poznawczy decydentów i narodów, co najdobitniej pokazują przypadki, w których — jak w Grecji około roku 430 p.n.e. — zaczyna się ona jawić jako jedyny możliwy sposób postępowania. Gdy Heidegger opisuje współczesną sobie technikę, to powiada, że zasadza się ona na „wyzwalaniu energii skrytej w przyrodzie” (Heidegger, 2007: 18). Wyzwalanie to nie przebiega jednak prosto, lecz jest zabezpieczane i kierowane tak, by energia płynęła w odpowiednią stronę. Podobnie jest z Wojną, która również jest pewnym sposobem użycia ludzkiej energii, a przy tym techniką zarządzania, zabezpieczania i kierowania jej przepływem. Jeśli chcemy być wierni językowi Heideggera, to w przypadku Wojny powinniśmy zresztą mówić raczej o istocie techniki niż technice:

Technika nie jest tym samym co istota techniki. Szukając istoty drzewa musimy dostrzegać, że to, co włada w każdym drzewie jako drzewie, samo nie jest drzewem, które 
można by spotkać pośród innych drzew. Tak więc również istota techniki nie jest czymś technicznym (Heidegger, 2007: 7).

Istotą wojny również nie jest coś wojennego — jak na przykład walka, lecz sposób, w jaki kształtuje ona percepcję, szereguje wartości oraz organizuje działania jednostek i narodów. W dyskursie wojennym przyjęło się mówić o konfliktach sprawiedliwych oraz niesprawiedliwych (Walzer, 2010). Przez podobne rozważania przebija przekonanie o neutralności wojny jako takiej. Przed takim rozumieniem przestrzega Heidegger, pisząc, że postrzeganie techniki jako czegoś neutralnego sprawia, że jesteśmy na nią zdani w największym stopniu to bowiem „czyni nas zupełnie ślepymi” (Heidegger, 2007: 7) na jej istotę. W podobnym tonie wypowiada się McLuhan, nie zgadzając się z powszechnym przekonaniem, „że znaczenie czy przekaz maszyny zależy nie od niej samej, lecz od sposobu jej wykorzystywania” (McLuhan, 1975: 45). Wojna nie jest tylko środkiem do osiągnięcia wcześniej wyznaczonych zadań, którego ocena zależy od moralnej słuszności celu. Jest techniką, która „kształtuje i kontroluje skalę i zakres działalności człowieka oraz jego stosunki z innymi” (McLuhan, 1975: 46). Jak jednak dostrzec i poddać krytycznej refleksji to, co reguluje stosunki w świecie? Czy nie wiąże się to przypadkiem z koniecznością stanięcia poza owym światem? Być może. Wojna jest na szczęście raczej „światkiem” niż wszechświatem, a więc spojrzenie na nią spoza niej wydaje się możliwe. Nie jest to jednak zadanie łatwe, gdyż jak każda technika:

nie oddziałuje na ludzi w sferze świadomie wyznawanych wartości czy pojęć, lecz po prostu wytrwale i nie napotykając na najmniejszy opór, zmienia współzależność między zmysłami i wzory percepcji świata (McLuhan, 1975: 57).

Zarówno Heidegger, jak i McLuhan widzą ratunek przed techniką w sztuce, która zdaniem tego drugiego może być swego rodzaju systemem wczesnego ostrzegania, umożliwiającym czynienie niewidzialnego widzialnym (Kukiełko-Rogozińska, 2014: 86). W przypadku badań nad wojną zadanie takie skutecznie realizuje Krzysztof Wodiczko, który w swoich pracach zwraca uwagę właśnie na struktury dyskursywne, w które wpisywane są wojenne wydarzenia i postaci. Struktury te pozwalają oświetlić heroiczny wymiar wojny, ukrywają zaś na przykład cierpienie weteranów (Wodiczko, 2003: 15-16).

Filozoficzne wyzwanie w obrębie zapobiegania wojnom również powinno polegać na oświetlaniu tego, co skrywa dyskurs wojenny. Jednym z jego elementów jest przekonanie o zewnętrznym wobec człowieka charakterze wojny. Modelowymi przykładami są tu Heraklitejskie rozumienie wojny jako ojca wszechrzeczy czy zdanie z Rzeźni numer piećc Kurta Vonneguta, zgodnie z którym zapobieganie wojnom przypomina walkę z lodowcami (Vonnegut, 1996: 15). Tymczasem Wojna jak każda inna technika nie jest ani nieprzezwyciężalnym 
żywiołem jak lodowiec, ani niezależnym od człowieka organizatorem bytów ojcem wszechrzeczy. W świetle badań Mead jest czymś nabytym, a wobec interpretacji w kategoriach ukutych przez Heideggera i McLuhana jawi się jako technika odciskająca piętno na ludzkim poznaniu. Twierdzenia te należy mocno odgraniczyć od wartościowań dotyczących natury ludzkiej. Prawdziwość tezy o akcydentalnym charakterze wojny w społecznościach ludzkich nie musi implikować optymizmu antropologicznego. Społeczności nieznające wojny czy traktujące ją jako przestarzały, nieoddziałujący już wynalazek mogą posiadać inne, być może nie mniej krwawe techniki zarządzania ludźmi.

Pytanie o powstrzymywanie wojen jest pytaniem o środki transmisji wojny jako narzędzia technicznego. Dokonuje się ona przez wychowanie, literaturę, dzieła sztuki czy traktaty o sztuce wojennej. Kultura przekazuje z pokolenia na pokolenie partyturę, która pozwala odtworzyć wojnę w momencie, kiedy zachodzi taka „potrzeba”. Za przykład weźmy literaturę, która w europejskim środowisku jest jednym z wyróżnionych środków jej transmisji jako wynalazku. Dzieła literackie stanowią wzór przeżywania i rozumienia wojny, który aktualizowany jest przez kolejne wieki. We wstępie do reportażu Wojna nie ma $w$ sobie nic z kobiety Aleksijewicz wspomina swoje dzieciństwo, pisząc:

W bibliotece szkolnej połowa książek dotyczyła wojny. To samo w wiejskiej i w centrum rejonowym, dokąd ojciec często jeździł pożyczać książki. Teraz chyba wiem, dlaczego tak było. To przecież nieprzypadkowe — ciągle tylko walczyliśmy albo szykowali się do wojny (Aleksijewicz, 2010: 8).

Jednym z polskich wzorów przeżywania wojny jest literatura romantyczna, która organizowała myślenie nie tylko o powstaniach narodowych, ale także o XX-wiecznych konfliktach. Romantyczny był kult Józefa Piłsudzkiego, „przedostatnie powstanie romantyczne” (Janion, 2018: 15) — jak Maria Janion nazywa zryw warszawiaków z roku 1944 — oraz niemal cała związana z nimi literatura. Ujęcia inne - jak Leopolda Buczkowskiego czy Tadeusza Borowskiego - są ciekawe właśnie dlatego, że stawiają wojenne medium w środowisku innym, niż do tego przywykliśmy, a więc pozwalają przyjrzeć mu się z odmiennej perspektywy. Pismo i wojna, jako dwa z kluczowych dla europejskiej kultury mediów, są zresztą ze sobą mocno związane. McLuhan przywoływał między innymi wpływ wynalezienia alfabetu na przekazanie władzy przez kapłanów na rzecz wojskowych. Pismo alfabetyczne stało się też istotną metodą przekazywania informacji na polu bitwy (McLuhan, 1975). W obrębie prowadzonych tu rozważań mowa jednak nie o piśmie jako środku użytecznym wewnątrz wojennej machiny, lecz o literaturze jako przekaźniku, który — wśród kilku innych — podtrzymuje istnienie wojny jako wynalazku. Czy należy więc zniszczyć biblioteki uginające się od wojennych partytur czekających na realizację? Taki model powstrzymywania wojen znów kierowałby nas ku myśleniu 
o nich jako o czymś zewnętrznym wobec człowieka. Jeśli natomiast wojna jest komponentem ludzkiego poznania, to jedynym sposobem na jej destrukcję jest zagłada ludzkości. To - jak łatwo się domyślić — da się dziśs osiągnąć głównie środkami wojennymi. Zadaniem nie jest więc destrukcja, lecz próba zrozumienia wpływu techniki na myślenie. Przydatną wskazówkę co do metody takiego działania oferuje McLuhan, który powiada, że aby zrozumieć wpływ niewidzialnego dotąd otoczenia, należy zetknąć je z jakimś innym otoczeniem. W przypadku literatury wojennej tym ostatnim może być właśnie dyskurs dotyczący techniki, w którym rozumiana jest ona jako sposób transmisji wojny jako wynalazku.

Reprodukcja wojny odbywa się na wielu poziomach, wśród których splot estetyki i ideologii zajmuje jedno z ważniejszych miejsc. Warto oczywiście podkreślić, że świadectwa wojenne nie są zwykle w założeniu szkicem, planem czy linią produkcyjną wojny. Nader często wynikają one po prostu z potrzeby opowieści, porządkowania doświadczenia czy przepracowania traumy. Przy okazji często bywają jednak także jednym z ontologicznych fundamentów wojny.

\section{ZAKOŃCZENIE}

Celem tekstu było rozważenie związków wojny z techniką oraz analiza wpływu istnienia wojny $\mathrm{w}$ społeczeństwach na postrzeganie rzeczywistości przez ich przedstawicieli. Inspirację dla podjętych w tekście badań stanowiła teza Margaret Mead, zgodnie z którą prowadzenie wojen nie jest ani wynikającą z ludzkich uwarunkowań biologicznych koniecznością, ani nieuniknioną konsekwencją rozwoju społeczeństw, lecz wynalazkiem. Z rozważań przeprowadzonych w tekście wynika, że wojnę można rozumieć dwojako — jako wydarzenie, ale także jako techniczne narzędzie sprawowania władzy. Wojna jako wynalazek analizowana była w tekście przy użyciu badających wpływ techniki na interpretację aktów percepcji koncepcji Martina Heideggera i Marshalla McLuhana. Samo istnienie wojny jako środka technicznego w obrębie polityki międzynarodowej odciska piętno na ludzkim poznaniu. Wojna kształtuje rozumienie podstawowych par pojęć politycznych takich jak: wróg-przyjaciel, wojna (jako wydarzenie) - pokój etc.

We wstępie postawiona została śmiała hipoteza, zgodnie z którą krytyczne studia nad wojną powinny zwrócić się raczej ku filozofii techniki niż ku etyce. Wydaje się, że badania dotyczące sposobu, w jaki istnienie wojny jako wynalazku ukształtowało rozumienie polityki międzynarodowej, rzeczywiście mogą mieć ogromne znaczenie w obrębie dociekań dotyczących wojny i pokoju. Mówiąc obrazowo, badania nad wpływem techniki na percepcję pozwalają sondować możliwość przekroczenia kolein percepcyjnych, w które wpadają niekiedy narody i decydenci. Sondowanie to nie musi prowadzić do naiwnego 
optymizmu - rozpoznanie wpływu techniki na społeczności niekoniecznie pociąga za sobą szybkie, realne zmiany. Nie będzie jednak innego końca wojny (jako wydarzenia) niż ten wynikający z jej ostatecznego odrzucenia (czy przekroczenia) jako potencjalnego narzędzia polityki międzynarodowej.

\section{BIBLIOGRAFIA}

Aleksijewicz, S. (2010). Wojna nie ma w sobie nic z kobiety. (Przeł. J. Czech). Wołowiec: Wydawnictwo Czarne.

Aleksijewicz, S. (2015). Cynkowi chłopcy. (Przeł. J. Czech). Wołowiec: Wydawnictwo Czarne.

Angier, T. (2010). Tecbne in Aristotle's Ethics. Crafting the moral life. London: Bloomsbury.

Arystofanes. (1977). Żaby (s. 449-527). W: Arystofanes. Komedie wybrane. (Przeł. A. Sandauer). Kraków: Wydawnictwo Literackie.

Arystoteles. (1996). Metafizyka. (Przeł. T. Żeleźnik). Lublin: Redakcja Wydawnictw Katolickiego Uniwersytetu Lubelskiego.

Arystoteles (2010). Zachęta do filozofii. Fizyka. (Przeł. K. Leśniak). Warszawa: Wydawnictwo Naukowe PWN.

Barkawi, T. \& Brighton, Sh. (2011). Powers of war: Fighting knowledge, and critique. International Political Sociology, 2, 126-143.

Baudrillard, J. (2006). Wojny w Zatoce Perskiej nie było. (Przeł. S. Królak). Warszawa: Sic!.

Clausewitz, C. von. (2010). O wojnie. (Przeł. A. Ciechowicz \& L. Kloc). Kraków: Mireki.

Derrida, J. (1993). Farmakon (s. 39-61). W: J. Derrida, Pismo filozofii. (Przeł. B. Banasiak). Kraków: Inter Esse.

Freud, Z. (2009). Aktualne uwag o wojnie i śmierci (s. 25-50). W: Z. Freud. Pisma spoteczne. (Przeł. R. Reszke). Kraków: Wydawnictwo KR.

Fukuyama, F. (1991). Czy koniec historii?. (Przeł. B. Stanosz). Warszawa: Wydawnictwo PoMost.

Heidegger, M. (1994). Bycie i czas. (Przeł. B. Baran). Warszawa: Państwowe Wydawnictwo Naukowe.

Heidegger, M. (2007). Pytanie o technikę (s. 7-38). W: M. Heidegger. Odczyty i rozprawy. (Przet. J. Mizera). Warszawa: Aletheia.

Huizinga, J. (2018). Jesień średniowiecza. (Przeł. R. Stiller). Kraków: vis-à-vis.

Jaeger, W. (1962). Paideia. (Przeł. M. Plezia). Warszawa: Instytut Wydawniczy Pax.

Janion, M. (2018). Zmierzch paradygmatu (s. 5-37). W: M. Janion. „Czy będziesz wiedziat, co przeżytes". Warszawa: Sic!.

Jünger, E. (2016). Perfekcja techniki. (Przet. W. Kunicki). Warszawa: Kronos.

Lazenby, J.F. (2018). Wojna peloponeska. Historia militarna. (Przeł. A. Dudziński). Oświęcim: Napoleon $\mathrm{V}$.

Levinas, E. (2002). Catość i nieskończoność. Esej o zewnętrzności. (Przeł. B. Skarga). Warszawa: Napoleon V.

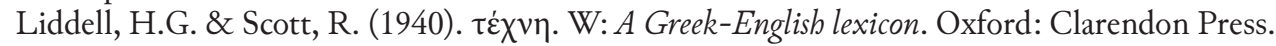
Online: http://www.perseus.tufts.edu/hopper/text?doc=Perseus:text:1999.04.0057:entry$=$ te $/ \mathrm{xnh}(29.10 .2020)$.

Kozak, M. (2014). Wojna jako doświadczenie przemocy bycia w myśli Emmanuela Levinasa. Kwartalnik Filozoficzny, 42(2), 103-116.

Ksenofont. (1857). Ekonomik. (Przeł. A. Bronikowski). Poznań: Księgarnia Jana Konstantego Żupańskiego. 
Kukiełko-Rogozińska, K. (2014). Między naukq a sztuka. Teoria i praktyka artystyczna w ujęciu Marsballa McLubana. Warszawa: Narodowe Centrum Kultury.

Mandrick, W. (2003). The ontology of war. Buffalo: University at Buffalo.

McLuhan, M. (1975). Przekaźniki, czyli przedłużenie człowieka (s. 43-209). W: M. McLuhan. Wybór pism. (Przeł. K. Jakubowicz). Warszawa: Wydawnictwo Artystyczne i Filmowe.

Mead, M. (1990). Warfare is only an invention - not a biological necessity. Dolphin Reader, 2, 406-411.

Mizera, J. (2006). W strone filozofii niemetafizycznej. Martina Heideggera droga do innego myślenia. Kraków: Wydawnictwo Uniwersytetu Jagiellońskiego.

Nordin, A.H.M. \& Öberg, D. (2014). Targeting the ontology of war: From Clausewitz to Baudrillard. Millennium, 2(43), 392-410.

Parry, R. (2020). Episteme and techne. W: E.N. Zalta (Red.). The Stanford encyclopedia of philosophy. Online: https://plato.stanford.edu/archives/fall2014/entries/episteme-techne/\&gt (01.01.2020).

Reeve, C.D.C. (2003). Plato's Metaphysics of morals. Oxford Studies in Ancient Philosophy, 25, 39-58.

Rosecrance, R. (1986). The rise of trading state: commerce and conquest in the modern world. New York: Basic Books.

Schmitt, C. (2012). Pojęcie polityczności (s. 245-314). W: C. Schmitt. Teologia polityczna i inne pisma. (Przeł. M.A. Cichocki). Warszawa: Wydawnictwo Aletheia.

Toffler, A. \& Toffler, H. (2006). Wojna i antywojna. (Przeł. B. Budrecka \& L. Budrecki). Poznań: Wydawnictwo Kurpisz S.A.

Tukidydes. (1988). Wojna peloponeska. (Przeł. K. Kumaniecki). Warszawa: Czytelnik.

Turski, M. (2020). „Jedenaste przykazanie: nie bądź obojętny”. Przemówienie Mariana Turskiego, b. więźnia Auschwitz. Online: https://natemat.pl/297833,cale-przemowienie-mariana-turskiego-b-wieznia-auschwitz-nie-badz-obojetny (28.02.2020).

Virillo, P. (2008). Prędkość i polityka. (Przeł. S. Królak). Warszawa: Sic!.

Vonnegut, K. (1996). Rzeźnia numer pięć. (Przeł. L. Jęczyk). Warszawa: Zysk i S-ka.

Walzer, M. (2010). Wojny sprawiedliwe i niesprawiedliwe. (Przeł. M. Szczubiałka). Warszawa: Wydawnictwo Naukowe PWN.

Wittgenstein, L. (1997). Tractatus logico-philosophicus. (Przeł. B. Wolniewicz). Warszawa: Wydawnictwo Naukowe PWN.

Wodiczko, K. (2003). Obalanie wojen. (Przeł. P. Łopatka). Kraków: Muzeum Sztuki Współczesnej w Krakowie. 